\title{
Combining Defects in a Single Nanographene: A Fully Helical Saddle Ribbon
}

\author{
Carlos M. Cruz \\ Silvia Castro-Fernández ${ }^{a}$ \\ Ermelinda Maçôas ${ }^{b}$ \\ Alba Millán ${ }^{a}$ \\ Araceli G. Campaña*a (iD) \\ ${ }^{a}$ Departamento de Química Orgánica, Facultad de \\ Ciencias, Universidad de Granada, Avda. Fuentenueva \\ s/n, 18071 Granada, Spain \\ araceligc@ugr.es \\ ${ }^{\text {b }}$ Centro de Química Estructural and Institute of Nano- \\ science and Nanotechnology (IN), Instituto Superior \\ Técnico, University of Lisbon, Av. Rovisco Pais, 1. \\ 1049-001 Lisboa, Portuga
}
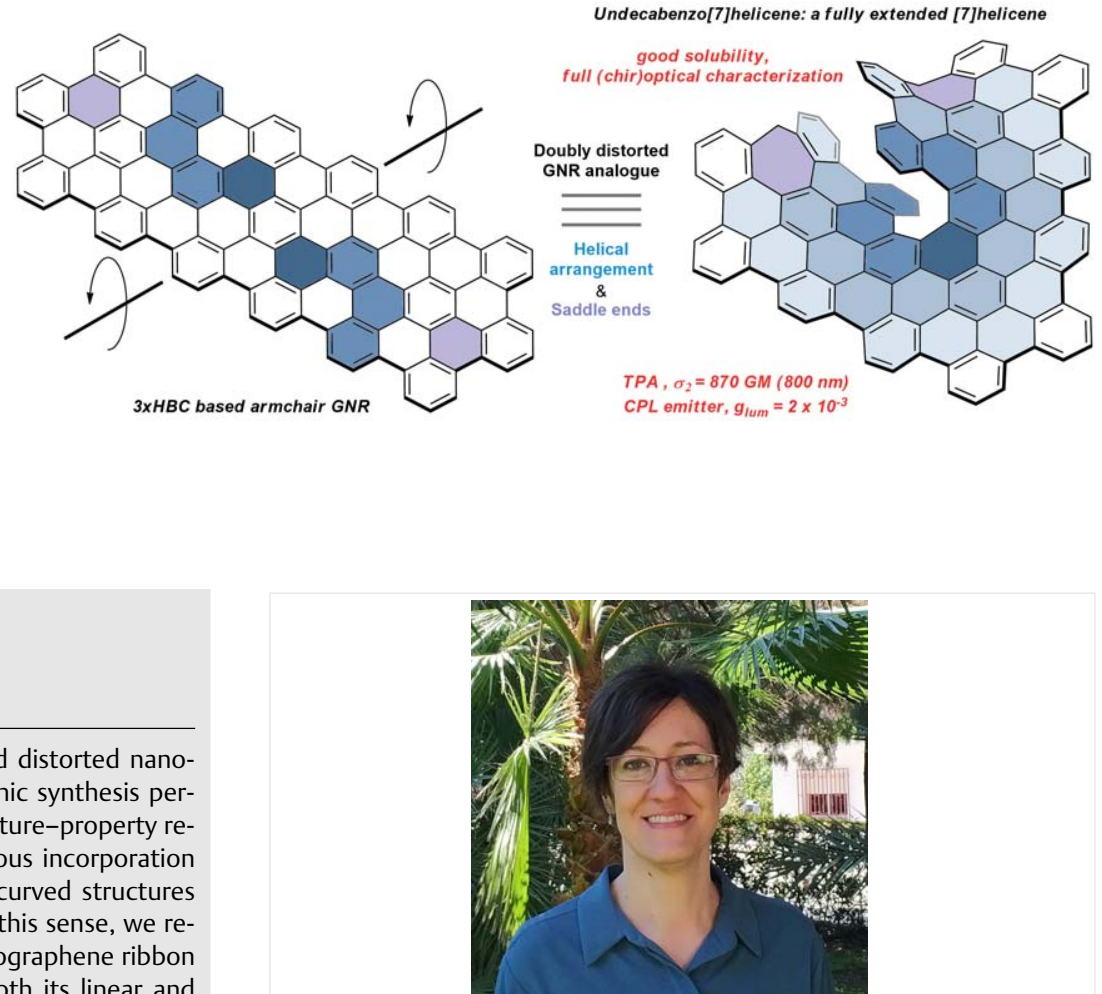

Received: 17.12.2018

Accepted after revision: 22.01.2019

Published online: 26.02 .2019

DOI: 10.1055/s-0037-1611729; Art ID: st-2018-p0812-sp

Abstract The controlled preparation of well-defined distorted nanographenes by a bottom-up approach based on organic synthesis permits the direct establishment of unprecedented structure-property relationships in carbon nanostructures. The simultaneous incorporation of various defects in nanographenes affords highly curved structures with novel or enhanced photophysical properties. In this sense, we recently reported a fully helical and saddle-shaped nanographene ribbon containing the first undecabenzo[7]helicene unit. Both its linear and nonlinear optical properties are enhanced in comparison with those of other partially $\pi$-extended [7]helicenes. Moreover, the new superhelicene exhibits the highest emission dissymmetry factor $\left(g_{\text {lum }}\right)$ reported to date for a homochiral nanographene. The combination of both nonlinear and chiroptical properties in nanographenes opens up new possible future applications for those distorted nanostructures.

1 Introduction

2 Synthesis of Embedded Seven-Membered Rings

3 Combination of Defects: Seven-Membered Rings and $\pi$-Extended Helicenes

4 Conclusions and Outlook

Key words nanographenes, helicenes, chirality, polycyclic aromatic hydrocarbons, optical properties, chiroptical properties

\section{Introduction}

Over the last two decades there has been intensive research into the design and synthesis of well-defined structures based on planar polycyclic aromatic hydrocarbons (PAHs) as benchmarks for the study of graphene. ${ }^{1}$ However, moving out from flatland opens the opportunity to explore new properties derived from the introduction of distortive elements that prompt a three-dimensional (3D) structural arrangement. One of the most frequently employed strategies for inducing nonplanarity in PAHs is the insertion of
Araceli G. Campaña received her Ph.D. in 2008 from the University of Granada under the supervision of Professors Juan M. Cuerva and J. E. Oltra, working on the development of new synthetic methods based on radical and organometallic chemistry. After a short postdoctoral appointment in the group of Professor D. J. Cárdenas at the UAM (Madrid), in 2010 she joined the group of Professor David A. Leigh at the University of Edinburgh as a postdoctoral researcher to work in the field of molecular machines. Since 2015, she has been a 'Ramón y Cajal' researcher at the University of Granada, where she has initiated her independent career. In 2015, she received an ERC starting grant. Her current research interests focus on the synthesis and study of curved distorted aromatics, searching for interesting (chir)optical and electronic properties.

nonhexagonal rings. In this sense, the introduction of a five-membered ring induces a bowl-shaped positive curvature, whereas the presence of a seven- or eight-membered ring favors negative folding. ${ }^{2}$ Various groups, including ours, have applied this concept to develop novel structures and have studied their properties, so that it is now well established that the physical and chemical characteristics of PAHs are altered by the presence of such imperfections, and that these properties can be tuned by synthetic design. ${ }^{3}$ The existence of curved architectures broadens the spectrum of applications of PAHs, and is appealing in a variety of fields, from wearable electronics to biological sensors. ${ }^{4}$ 
A second option for pushing $\pi$-systems toward 3D space is the introduction of carbo[n]helicenes. These structures are PAHs constituted by contiguous ortho-fused benzene rings that adopt a helical arrangement due to a conformational distortion imposed by steric strain..$^{5}$ This motif not only affects the topology of the molecule, but also confers chirality and, thereby, chiroptical properties. ${ }^{6}$ In this respect, enantiopure helically twisted nanographenes have been proposed as excellent candidates for the development of chiral optoelectronic devices. By exploring properties associated with chirality, such as circularly polarized luminescence $(\mathrm{CPL}){ }^{7}$ new materials with potential applications in organic electronics can be identified. This fact has brought the synthesis of homochiral nanographenes to the forefront in the field of organic materials, and new examples of multiple helicenes ${ }^{8}$ or novel hexa-peri-hexabenzocoronene (HBC)-based helicenes have been developed. ${ }^{9}$ Particular emphasis has been placed on the design of more sophisticated structures incorporating laterally $\pi$-extended helicenes to widen $\pi$-conjugation (Figure 1 ). ${ }^{10}$ Moreover, a combination of ring-size defects and homohelicity within a single molecule might be an interesting prospect, as superior or new properties might appear from the combination of the individual properties associated with each motif. Some examples have already been reported that combine enantiopure carbohelicenes with pentagonal carbocycles, ${ }^{11}$ but combinations containing saddle-shape heptagonal ones have received much less attention. ${ }^{12}$
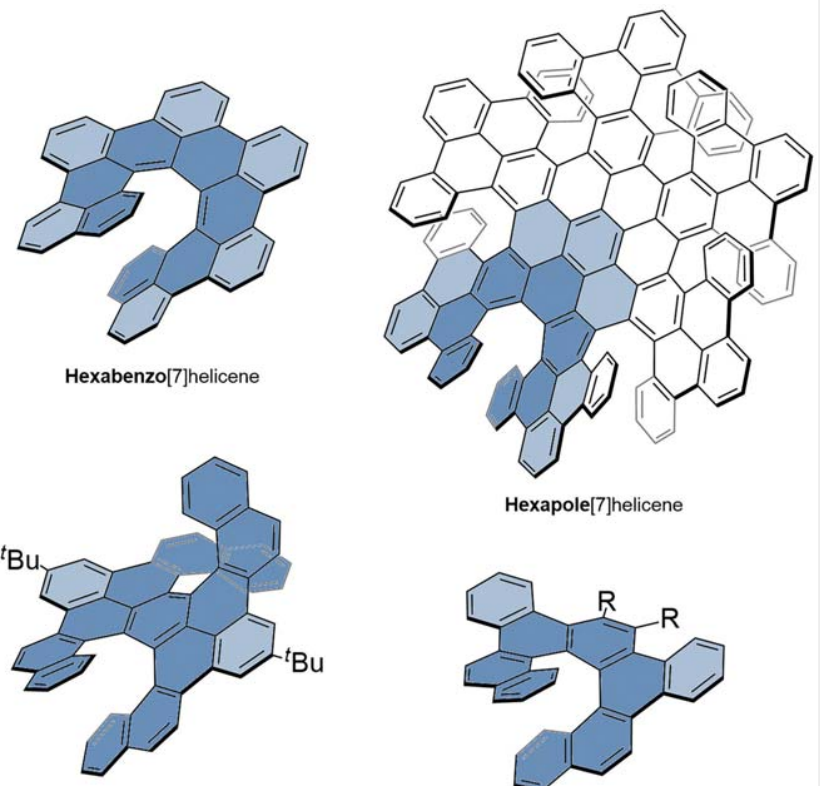

Hexapole[7]helicene

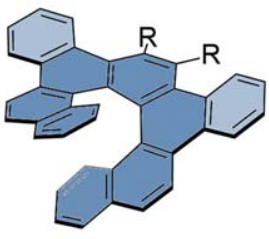

Double dibenzo[7]helicene

Dibenzo[7]helicene

Figure 1 Previously reported enantiopure $\pi$-extended carbo[7]helicene derivatives. $\mathrm{R}=4$ - $\mathrm{Tol}$ or $4-\mathrm{PPr}-\mathrm{C}_{6} \mathrm{H}_{4}$

\section{Synthesis of Embedded Seven-Membered Rings}

The design of well-defined distorted nanographenes requires reliable and efficient synthetic methods that permit the introduction of defects in selected positions. With regard to ring-size defects and, more precisely, seven-membered rings, several bottom-up approaches have been developed in recent years, which have boosted the synthesis of structures containing heptagonal carbocycles. The strategies developed so far are based on three different approaches (Scheme 1). The first approach relies on the use of starting materials that contain seven-membered rings, with subsequent construction of the surrounding aromatic scaffold [Scheme 1(a)]..$^{13}$ The second approach involves intramolecular cyclization reactions. One classic example is the Scholl reaction, ${ }^{14}$ a dehydrogenative intramolecular coupling of nonfunctionalized arenes mediated by a combination of a Lewis acid and an oxidant [Scheme 1(b); left]. Although this strategy has been widely applied in the synthesis

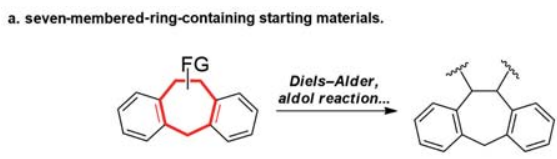

b. Intramolecular cyclization
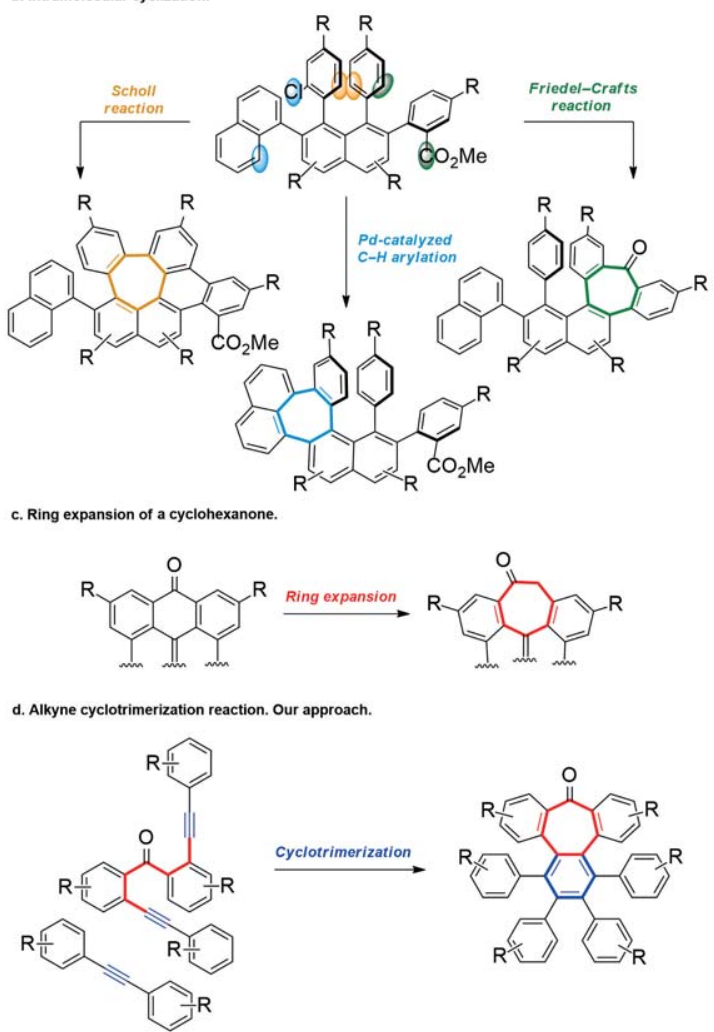

Scheme 1 Suitable synthetic approaches for the introduction of sevenmembered rings into PAHs 
of PAHs, ${ }^{12 a, 15}$ there are some cases in which the reaction is not fully predictable and/or controllable, as undesired rearrangements can occur. To avoid those issues, alternative strategies have been developed involving, for example, Friedel-Crafts reactions ${ }^{13 \mathrm{~b}}$ or palladium-catalyzed C-H arylations ${ }^{16}$ [Scheme 1(b); right and bottom]; although both strategies require prefunctionalized precursors, the outcome of the reaction is better controlled. A third approach, introduced recently, involves ring expansion of cyclohexanones to form cycloheptanones ${ }^{17}$ [Scheme 2(c)]. Our group has also contributed to this field with the development of a versatile and convergent strategy based on an intermolecular cobalt-catalyzed cyclotrimerization reaction, ${ }^{18}$ which permits not only the formation of the heptagonal ring, but also the installation of the polyphenylene aromatic core [Scheme 1(d)]. ${ }^{19}$ Adequate functionalization of the precursors provides further reactive sites for the enlargement of the $\mathrm{sp}^{2}$ carbon network. By following this strategy, we have synthesized various structures containing seven-membered rings, such as nanoribbons ${ }^{12 c}$ or [3]cumulenes derivatives. $^{20}$

\section{Combinations of Defects: Seven-Mem- bered Rings and $\pi$-Extended Helicenes}

In pursuit of the induction of strong chiroptical properties in $\pi$-extended nanographenes, we designed a strategy for synthesizing a ribbon-shaped nanographene fully arranged in a helicoidal shape. The best structural design would offer the advantage of incorporating both main features, namely a ribbon-extended PAH and a chiral helical arrangement, in one operation. ${ }^{21}$
One of our principal concerns when designing this extended nanographene was the solubility of the final compound, necessary for its adequate characterization. Unequivocal structural characterization of a nanographene is mandatory if its optical properties are to be studied, as minor impurities might falsify the results. We were aware that other promising, purely hexagonal, PAHs reported in this field had been barely characterized and that their properties had been scarcely studied due to difficulties in manipulation. In this sense, the application of our above-mentioned method for inducing bending of the polyaromatic surface by introducing seven-membered rings into the structure would induce an extra curvature thereby enhancing the solubility and processability of the product. Moreover, the distortion caused by the heptagonal rings was expected to affect the optoelectronic properties of the final $\mathrm{PAH}$ and, together with the incorporation of bulky tert-butyl groups, would hinder $\pi-\pi$ stacking interactions, preventing spontaneous precipitation of the products.

On the basis of our previous experience and reported results from other authors, we designed a straightforward synthetic route to a fully $\pi$-extended helical ribbon $\mathbf{1}$ (Scheme 2). The creation of the $\pi$-extended polyaromatic surface of our superhelicene was based on the attachment of three (HBC) units, two of which bearing seven-membered rings constituting the edges of the nanohelicoid, with the other quasi-flat $\mathrm{HBC}$ forming the middle part. The building of the central HBC by means of a Diels-Alder reaction (Scheme 2; Step d) forced the heptagon-containing HBCs on the edges to move closer, so that they were partially superimposed, driving the formation of a central carbo[7]helicene moiety totally surrounded by aromatic rings. This is the first fully $\pi$-extended carbo[7]helicene, or in oth-

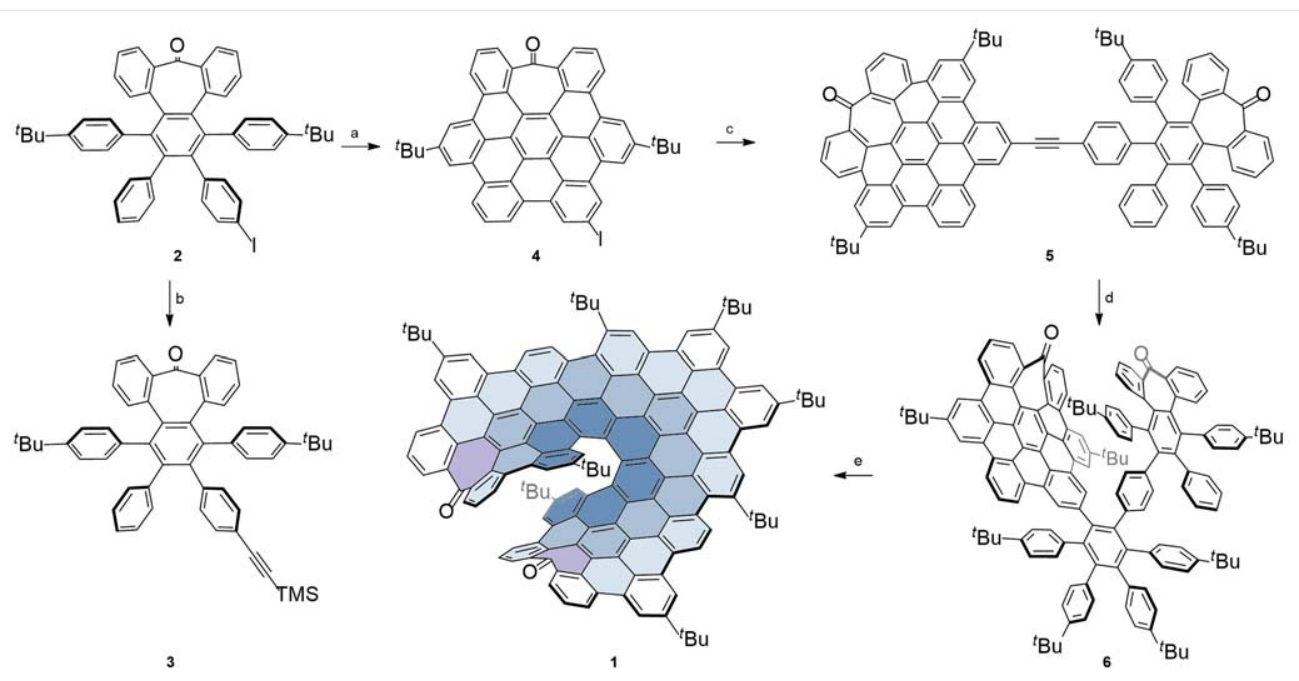

Scheme 2 Synthesis of compound 1. Reagents and conditions: (a) DDQ, $\mathrm{F}_{3} \mathrm{CSO}_{3} \mathrm{H}, \mathrm{CH}_{2} \mathrm{Cl}_{2}, 0{ }^{\circ} \mathrm{C}, 10 \mathrm{~min}, 86 \%$; (b) $\mathrm{TMSC} \equiv \mathrm{CH}_{1} \mathrm{PdCl}_{2}\left(\mathrm{PPh}_{3}\right)_{2}, \mathrm{Cul}, \mathrm{Et} \mathrm{t}_{3} \mathrm{~N}, \mathrm{THF}$, r.t., 16 h, 99\%; (c) 3, $\mathrm{PdCl}_{2}\left(\mathrm{PPh}_{3}\right)$, Cul, Et ${ }_{3} \mathrm{~N}, \mathrm{DBU}, \mathrm{THF}, \mathrm{H}_{2} \mathrm{O}$, reflux, 24 h, 84\%; (d) 2,3,4,5-tetrakis(4-tert-butylphenyl)cyclopenta-2,4-dien-1-one, $\mathrm{Ph}{ }_{2} \mathrm{O}$, reflux, $10 \mathrm{~h}, 75 \%$; (e) DDQ, $\mathrm{F}_{3} \mathrm{CSO}_{3} \mathrm{H}, \mathrm{CH}_{2} \mathrm{Cl}_{2}, 0{ }^{\circ} \mathrm{C}, 10 \mathrm{~min}, 7 \%$. 

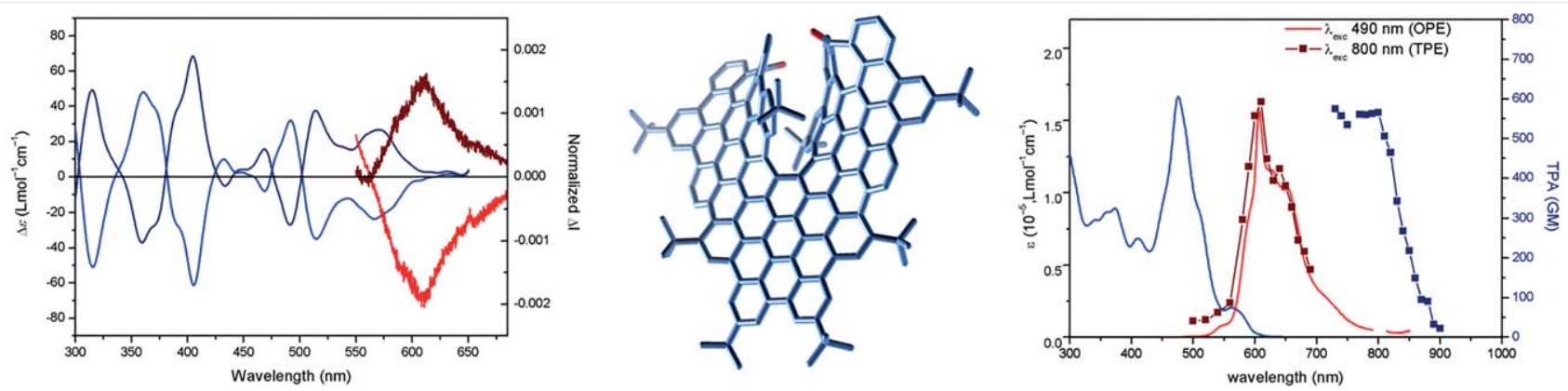

Figure 2 Left: ECD and CPL spectra of $(M)-1$ (blue and red, respectively) and (P)-1 (navy and magenta, respectively). Middle: DFT-CAMB3LYP-6-31G (d,p)-optimized geometry of (M)-1. Right: UV-vis (blue), two-photon absorption (navy squares), one-photon emission (red), and two-photon emission (magenta squares) spectra of $\mathbf{1}$.

er words, the first reported undecabenzo[7]helicene (see Figure 1 for previously reported enantiopure $\pi$-extended carbo[7]helicenes).

Once we had obtained the desired product and were satisfied that it was highly soluble in a range of organic solvents that would permit its unequivocal structural characterization, we proceeded to study its photophysical properties. On one hand, we had expected to obtain interesting linear and nonlinear optical properties derived from the extended aromatic surface forming the ribbon nanographene 1. Thus, one- and two-photon absorption (OPA and TPA) and one- and two-photon emission (OPE and TPE) spectra were recorded (Figure 2; right). Remarkably, the fluorescence emission maximum was considerably red-shifted $(606 \mathrm{~nm})$ in comparison with that of other [7]helicenes (Table $\left.1 ; \lambda_{\mathrm{em}}\right)$, as expected from a fully $\pi$-extended structure. Furthermore, independently of the excitation wavelength, overlapping of the upconverted emission (TPE) with the one-photon-induced emission (OPE) was observed. The TPA cross-section reached 870 Goeppert Mayer (GM) units at about $800 \mathrm{~nm}$. This high TPA value represents the first success in the improvement of the tailored structure, a remarkable 6.7-fold increase in comparison with that of carbon nanodots ${ }^{22}$ or with that of our previous synthesized distort-

Table 1 Main Photophysical Properties of 1, [7]Helicene and Structurally Related $\pi$-Extended Carbo[7]helicenes

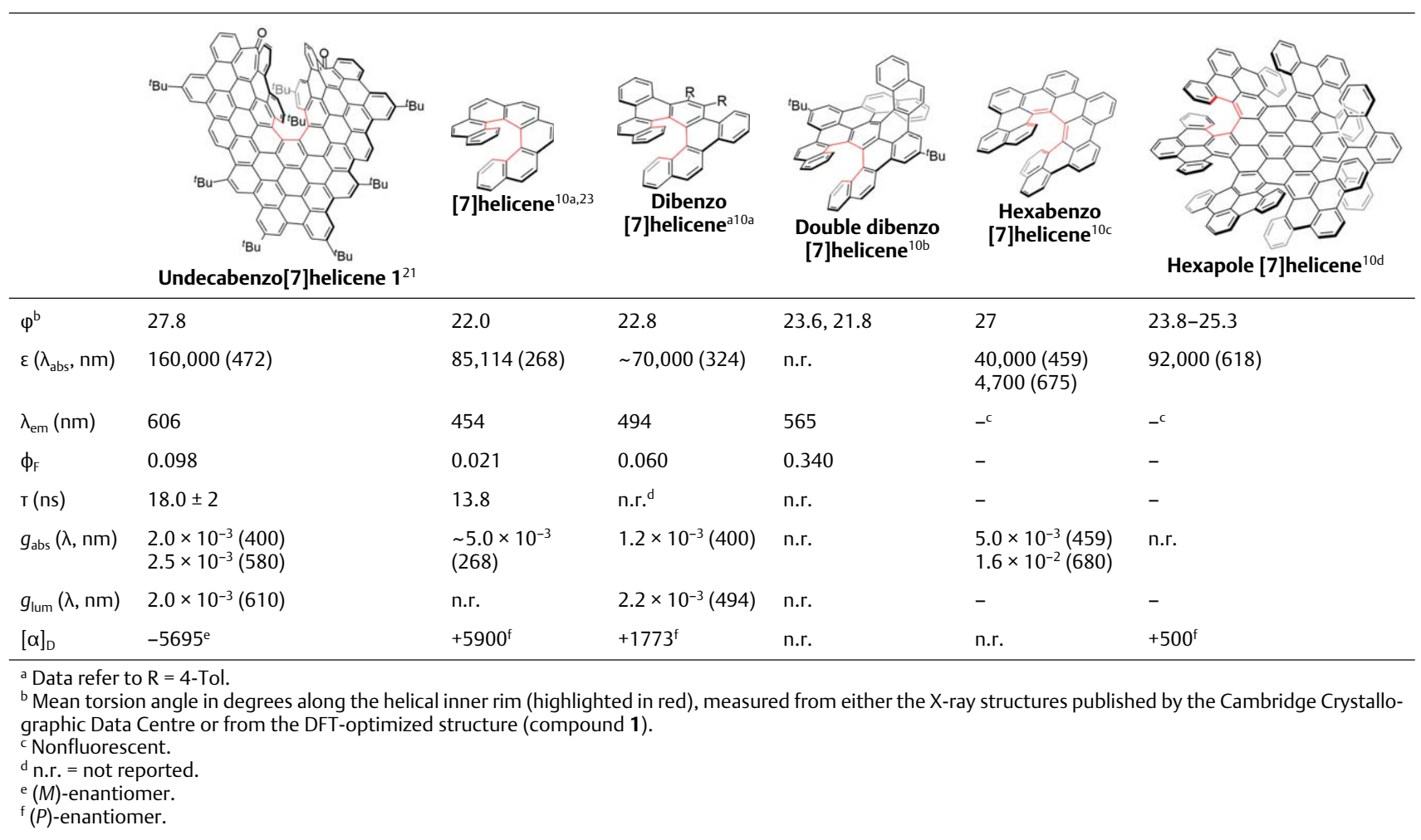


ed ribbon nanographene with push-pull character (130 GM at $\sim 60 \mathrm{~nm}) .{ }^{12 \mathrm{c}}$ In this sense, the OPA absorption coefficient was also markedly higher than those of structurally related $\pi$-extended [7] helicenes (Table $1 ; \varepsilon$ ). The luminescence quantum yield (Table $\left.1 ; \varphi_{\mathrm{F}}\right)$ of $\mathbf{1}\left(9.8 \%\right.$ in $\left.\mathrm{CH}_{2} \mathrm{Cl}_{2}\right)$ showed an intense increase compared with those of other $\pi$-extended [7]helicenes, and its value was almost five times that of heptahelicene, ${ }^{23}$ which led to about a ninefold increase in brightness $\left(\varepsilon \times \varphi_{\mathrm{F}}\right)$. We attribute these outstanding values to the particular aromatic backbone of nanographene $\mathbf{1}$, in which electrons can easily move and can even be accommodated, as also suggested by the nine reduction potentials observed during voltammetry experiments (down to $-3 \mathrm{~V}$ versus $\mathrm{Fc} / \mathrm{Fc}^{+}$).

The presence of the disubstituted central helicene moiety $^{24}$ induces a large torsion angle (Table $1, \varphi$ ) resulting in two possible enantiomers of $\mathbf{1}$ and, consequently, potential chiroptical properties. Therefore, we subjected $\mathbf{1}$ to chiral resolution by HPLC, followed by measurements of the emission and absorption chiroptical properties of the enantiomers (Figure 2; left). The two separated samples were configurationally stable and presented intense mirror-image electronic circular dichroism (ECD) spectra with a $g_{\text {abs }}$ value of $2.0 \times 10^{-3}$ at the highest Cotton-effect band $(400 \mathrm{~nm})$ and, more importantly, a $g_{\text {abs }}$ value of $2.5 \times 10^{-3}$ at the lowest absorption band ( $580 \mathrm{~nm})$, which is related to the emission properties. The circularly polarized luminescence (CPL) spectra of both enantiomers of $\mathbf{1}$ were also mirror images, presenting an emission dissymmetry factor $\left(g_{\text {lum }}\right)$ of $2.0 \times$ $10^{-3}$, which is in the same range of that of the absorption mode. This value represents an increase of one order of magnitude over that of the sole reported example of a nanographene with a CPL-emission capability. ${ }^{12 c}$

As mentioned above, the overall doubly distorted nanographene 1 exhibits improved (chir)optical properties in comparison with previously described structurally related $\pi$-extended carbo[7] helicenes (see Table 1 ). In particular, 1 showed a high fluorescence at low energy (606 nm) with a remarkable long lifetime (18 ns) and a high dissymmetry factor $\left(g_{\text {lum }} \approx 2 \times 10^{-3}\right)$. Moreover, the excited state responsible for the chiral emission can also be reached by excitation with two photons of low energy (800 nm), which constitutes a fundamental basis for the future development of two-photon circularly polarized luminescence, the emission analogue to known two-photon circular dichroism (TPCD). ${ }^{25}$

\section{Conclusions and Outlook}

Moving from planarity in the field of nanographenes broadens the range of opportunities for using these new distorted architectures as organic functional materials. The combination of ring-size defects and fully $\pi$-extended heli- cenes induces the appearance of several interesting properties in a single molecule, which could pave the way toward the development of new applications related to spintronics, photonics, and optoelectronics. For instance, as demonstrated by our structure 1, nonlinear optics and chiroptical properties can be merged in a single structure, which could give rise to the development of new approaches based on two-photon CPL, as an absorption analogue to TPCD; this could combine the advantages of both responses with a reduced linear absorption and scattering in near-infrared excitation wavelengths. The linear and nonlinear optical characterization provide detailed structural and conformational information about the homochiral skeletons. In this sense, the introduction of multiple extended helical and ring-size defects in nanographenes might lead to further improvements in their linear, nonlinear, and chiroptical properties.

Moreover, to facilitate the ultimate applicability of distorted nanographenes, it is crucial to predict their properties fully from their structures. Although outstanding and intense work has been carried out in attempts to pursue this aim, it is not yet possible. This challenge provides a motivation for the construction and study of new well-defined distorted and curved PAHs that could expand the wide range of architectures available and would help to shed light on the rationalization of their structure-property relationships.

\section{Funding Information}

This work was supported by the European Research Council (ERC) under the European Union's Horizon 2020 research and innovation program (ERC-2015-STG-677023) and the Ministerio de Economía y Competitividad (Spain) (CTQ2015-70283-P, BES-2016-076371, IJCI2016-27793 and RyC-2013-12943). E.M. thanks the Fundação para a Ciência e a Tecnologia for financial support (UID/NAN/50024/2013 and IF/00759/2013)

\section{Acknowledgment}

We thank the CSIRC-Alhambra and the Unidad de Excelencia Química Aplicada a Biomedicina y Medioambiente (UGR)

\section{References}

(1) (a) Wu, J.; Pisula, W.; Müllen, K. Chem. Rev. 2007, 107, 718. (b) Narita, A.; Wang, X.-Y.; Feng, X.; Müllen, K. Chem. Soc. Rev. 2015, 44, 6616.

(2) Yazyev, O. V.; Chen, Y. P. Nat. Nanotechnol. 2014, 9, 755.

(3) (a) Márquez, I. R.; Castro-Fernández, S.; Millán, A.; Campaña, A. G. Chem. Commun. 2018, 54, 6705. (b) Pun, S. H.; Miao, Q. Acc. Chem. Res. 2018, 51, 1630 .

(4) (a) Deng, S.; Berry, V. Mater. Today 2016, 19, 197. (b) Eftekhari, A.; Garcia, H. Mater. Today Chem. 2017, 4, 1.

(5) Shen, Y.; Chen, C.-F. Chem. Rev. 2012, 112, 1463.

(6) Gingras, M.; Félix, G.; Peresutti, R. Chem. Soc. Rev. 2013, 42, 1007. 
(7) (a) Sánchez-Carnerero, E. M.; Agarrabeitia, A. R.; Moreno, F.; Maroto, B. L.; Muller, G.; Ortiz, M. J.; de la Moya, S. Chem. Eur. J. 2015, 21, 13488. (b) Kumar, J.; Nakashima, T.; Kawai, T. J. Phys. Chem. Lett. 2015, 6, 3445. (c) Longhi, G.; Castiglioni, E.; Koshoubu, J.; Mazzeo, G.; Abbate, S. Chirality 2016, 28, 696.

(8) (a) Li, C.; Yang, Y.; Miao, Q. Chem. Asian J. 2018, 13, 884. (b) Schuster, N. J.; Hernández Sánchez, R.; Bukharina, D.; Kotov, N. A.; Berova, N.; Ng, F.; Steigerwald, M. L.; Nuckolls, C. J. Am. Chem. Soc. 2018, 140, 6235.

(9) (a) Reger, D.; Haines, P.; Heinemann, F. W.; Guldi, D. M.; Jux, N. Angew. Chem. Int. Ed. 2018, 57, 5938. (b) Evans, P. J.; Ouyang, J.; Favereau, L.; Crassous, J.; Fernández, I.; Perles, J.; Martín, N. Angew. Chem. Int. Ed. 2018, 57, 6774.

(10) (a) Buchta, M.; Rybáček, J.; Jančařík, A.; Kudale, A. A.; Buděšínský, M.; Chocholoušová, J. V.; Vacek, J.; Bednárová, L.; Císařová, I.; Bodwell, G. J.; Starý, I.; Stará, I. G. Chem. Eur. J. 2015, 21, 8910. (b) Hu, Y.; Wang, X.-Y.; Peng, P.-X.; Wang, X.-C.; Cao, X.-Y.; Feng, X.; Müllen, K.; Narita, A. Angew. Chem. Int. Ed. 2017, 56, 3374. (c) Nakakuki, Y.; Hirose, T.; Sotome, H.; Miyasaka, H.; Matsuda, K. J. Am. Chem. Soc. 2018, 140, 4317. (d) Zhu, Y.; Xia, Z.; Cai, Z.; Yuan, Z.; Jiang, N.; Li, T.; Wang, Y.; Guo, X.; Li, Z.; Ma, S.; Zhong, D.; Li, Y.; Wang, J. J. Am. Chem. Soc. 2018, 140, 4222. (e) Yamano, R.; Shibata, Y.; Tanaka, K. Chem. Eur. J. 2018, 24, 6364.

(11) (a) Fujikawa, T.; Preda, D. V.; Segawa, Y.; Itami, K.; Scott, L. T. Org. Lett. 2016, 18, 3992. (b) Kato, K.; Segawa, Y.; Scott, L. T.; Itami, K. Angew. Chem. Int. Ed. 2018, 57, 1337. (c) FernándezGarcía, J. M.; Evans, P. J.; Medina Rivero, S.; Fernández, I.; García-Fresnadillo, D.; Perles, J.; Casado, J.; Martín, N. J. Am. Chem. Soc. 2018, 140, 17188.

(12) (a) Pradhan, A.; Dechambenoit, P.; Bock, H.; Durola, F. J. Org. Chem. 2013, 78, 2266. (b) Fujikawa, T.; Segawa, Y.; Itami, K. J. Org. Chem. 2017, 82, 7745. (c) Cruz, C. M.; Márquez, I. R.; Mariz, I. F. A.; Blanco, V.; Sánchez-Sánchez, C.; Sobrado, J. M.; Martín-Gago, J. A.; Cuerva, J. M.; Maçôas, E.; Campaña, A. G. Chem. Sci. 2018, 9, 3917.
(13) (a) Luo, J.; Xu, X.; Mao, R.; Miao, Q. J. Am. Chem. Soc. 2012, 134, 13796. (b) Cheung, K. Y.; Xu, X.; Miao, Q. J. Am. Chem. Soc. 2015, $137,3910$.

(14) Grzybowski, M.; Skonieczny, K.; Butenschön, H.; Gryko, D. T. Angew. Chem. Int. Ed. 2013, 52, 9900.

(15) For selected examples, see: (a) Mughal, E. U.; Kuck, D. Chem. Commun. 2012, 48, 8880. (b) Kawasumi, K.; Zhang, Q.; Segawa, Y.; Scott, L. T.; Itami, K. Nat. Chem. 2013, 5, 739.

(16) Kawai, K.; Kato, K.; Peng, L.; Segawa, Y.; Scott, L. T.; Itami, K. Org. Lett. 2018, 20, 1932.

(17) Pun, S. H.; Chan, C. K.; Luo, J.; Liu, Z.; Miao, Q. Angew. Chem. Int. Ed. 2018, 57, 1581.

(18) (a) Vollhardt, K. P. C. Angew. Chem. 1984, 96, 525. (b) Agenet, N.; Gandon, V.; Vollhardt, K. P. C.; Malacria, M.; Aubert, C. J. Am. Chem. Soc. 2007, 129, 8860.

(19) Márquez, I. R.; Fuentes, N.; Cruz, C. M.; Puente-Muñoz, V.; Sotorrios, L.; Marcos, M. L.; Choquesillo-Lazarte, D.; Biel, B.; Crovetto, L.; Gómez-Bengoa, E.; González, M. T.; Martin, R.; Cuerva, J. M.; Campaña, A. G. Chem. Sci. 2017, 8, 1068.

(20) Jiménez, V. G.; Tapia, R.; Medel, M. A.; Mariz, I. F. A.; Ribeiro, T.; Blanco, V.; Cuerva, J. M.; Maçôas, E.; Campaña, A. G. Chem. Commun. 2018, 54, 3359.

(21) Cruz, C. M.; Castro-Fernández, S.; Maçôas, E.; Cuerva, J. M.; Campaña, A. G. Angew. Chem. Int. Ed. 2018, 57, 14782.

(22) Santos, C. I. M.; Mariz, I. F. A.; Pinto, S. N.; Gonçalves, G.; Bdikin, I.; Marques, P.; Neves, M.; Martinho, J. M. G.; Maçôas, E. M. S. Nanoscale 2018, 10, 12505.

(23) (a) Vander Donckt, E.; Nasielski, J.; Greenleaf, J. R.; Birks, J. B. Chem. Phys. Lett. 1968, 2, 409. (b) Joly, M.; Defay, N.; Martin, R. H.; Declerq, J. P.; Germain, G.; Soubrier-Payen, B.; Van Meerssche, M. Helv. Chim. Acta 1977, 60, 537. (c) Nakai, Y.; Mori, T.; Inoue, Y. J. Phys. Chem. A 2012, 116, 7372.

(24) Ravat, P.; Hinkelmann, R.; Steinebrunner, D.; Prescimone, A.; Bodoky, I.; Juríček, M. Org. Lett. 2017, 19, 3707.

(25) (a) Jansík, B.; Rizzo, A.; Ågren, H.; Champagne, B. J. Chem. Theory Comput. 2008, 4, 457. (b) Toro, C.; De Boni, L.; Lin, N.; Santoro, F.; Rizzo, A.; Hernandez, F. E. Chem. Eur. J. 2010, 16, 3504. 